\title{
Nível socioeconômico e cor/raça em pesquisas sobre efeito-escola
}

\section{CRISTINA COURI*}

\section{RESUMO}

O texto apresenta uma proposta para a desagregação do índice de nível socioeconômico utilizado nas investigaçóes sobre efeito-escola e escolas eficazes em quatro dimensóes: capital econômico, capital cultural, capital social de convivência e capital social de intervenção, com o uso de novas técnicas, entre elas a técnica GOM. Propõe também a introdução, nos modelos hierárquicos utilizados nestas pesquisas, das variáveis de interação entre a cor/raça e os recursos familiares dos alunos.

Palavras-chave: Desigualdades Sociais, Raça, Recursos financeiros, Famílias, Escolas.

\section{RESUMEN}

El texto presenta una propuesta para la desagregación del índice de nivel socioeconómico utilizado en las investigaciones sobre el efecto-escuela y escuelas eficaces a partir de la contemplación de cuatro dimensiones: capital económico, capital cultural, capital social de convivencia y capital social de intervención; con el uso de nuevas técnicas, entre ellas la técnica GOM. Se propone también la introducción, en los modelos jerárquicos utilizados en estas investigaciones, de variables de interacción entre el color/raza y los recursos familiares de los alumnos.

Palabras clave: Desigualdad social, Raza, Recursos financieros, Familias, Escuelas.

\section{ABSTRACT}

This paper presents a proposal to breakdown the socioeconomic status index used in studies on school effects and effective schools into four dimensions: economic capital, cultural capital, relational social capital and intervention social capital with the use of new techniques,

* Analista em Educação do Instituto Oi Futuro (crislcouri@gmail.com). 
including the GOM technique. It also presents a proposal to introduce, in the hierarchical models used in these studies, the variables of interaction between color/race and the student's family resources.

Keywords: Social inequality, Race, Financial resources, Families, Schools. 


\section{INTRODUÇÃo}

A pesquisa sobre efeito-escola tem por objetivo entender de que forma a variação no desempenho dos alunos pode ser atribuída às suas diferenças, ou às escolas que frequentam. O efeito-escola pode ser entendido como o "valor agregado" pela escola aos estudantes. As escolas com melhores condiçōes poderiam contribuir mais e melhor para um aumento do desempenho médio de seu alunado, independentemente da origem social deste; sáo as ditas "escolas eficazes". Distancia-se assim da ideia de que a origem social e o contexto familiar do aluno são os únicos fatores explicativos do seu desempenho e da sua trajetória escolar, destacando outros agentes sociais neste processo.

Estudos empíricos, que analisaram a relação entre os fatores escolares e o desempenho dos estudantes, se preocuparam em analisar como a introduçáo desses fatores modificava a influência que o nível socioeconômico e a cor/raça do aluno exerciam sobre o desempenho escolar. Além de influenciar o desempenho médio dos estudantes, algumas práticas e fatores escolares que se revelaram promotores de eficácia (aumento do desempenho) podem acentuar as desigualdades existentes entre alunos de diferentes estratos socioeconômicos e cor/raça. A preocupação maior passa a ser náo só a garantia de um ensino público de qualidade, mas também da equidade nas escolas brasileiras. Para tal, é preciso compreender os mecanismos e processos educacionais que produzem e reproduzem desigualdades, de forma a transformar o ambiente escolar em um elemento fundamental para a redução do impacto das diferenças sociais nas trajetórias educacionais.

O presente artigo apresenta parte do trabalho de pesquisa "Recursos familiares, efeito-escola e desigualdade educacional entre brancos, pardos e pretos no Brasil"'. A sua contribuiçáo para a literatura sobre efeito-escola foi a desagregação do índice de nível socioeconômico em quatro dimensóes: capital econômico, capital cultural, capital social de convivência e capital social de intervenção, e a introdução nos modelos hierárquicos dos termos de interação entre a cor/raça e os recursos familiares dos alunos. Apresentam-se aqui novas técnicas para o cálculo das dimensōes dos bens familiares, e enfatiza-se a aplicação para estudos sobre desempenho de alunos de cor/raça distinta. Isto porque, conforme se mostrará adiante, cada uma dessas dimensóes possui efeitos diferenciados sobre a cor/raça do estudante.

Este artigo está dividido em seis seçōes. A próxima seção contextualiza as pesquisas sobre efeito-escola e a importância da cor/raça no rendimento escolar dos alu-

\footnotetext{
${ }^{1}$ Dissertaçáo de conclusão de Mestrado em Estudos Populacionais e Pesquisas Sociais da Escola Nacional de Ciências Estatísticas - ENCE/IBGE, em agosto de 2008, sob orientação do Prof. Dr. Kaizô Iwakami Beltrão.
} 
nos. A terceira seçáo descreve as dimensóes do índice de nível socioeconômico mais comuns e apresenta uma metodologia para a sua desagregação. A quarta seção mostra a aplicaçáo dos novos índices principalmente nas pesquisas sobre efeito-escola que analisam a influência da cor/raça dos alunos. A quinta seção aponta, a título de exemplo, os resultados encontrados na pesquisa, com dados do Saeb de 2003, último ano disponível na época. A sexta e última seção conclui a discussão.

\section{PESQUISAS SOBRE EFEITO-ESCOLA E COR/RAÇA}

Os estudos sobre eficácia e equidade escolar apontam a cor/raça como variável importante para explicar o desempenho do aluno. A análise da influência dos fatores escolares na redução do impacto da cor e na promoçáo da equidade entre estudantes brancos e não-brancos é um campo em expansáo. Nessa análise parte-se da premissa de que a origem das diferenças observadas no desempenho entre alunos brancos, pardos e pretos não encontra explicação somente na origem socioeconômica. $\mathrm{O}$ impacto difere segundo aspectos da escolarização e variaçóes nos contextos escolares.

A ideia é de que as políticas públicas não deveriam apenas se direcionar para a melhoria do desempenho e para a redução da influência da origem socioeconômica, mas também para a diminuiçáo da influência que a cor/raça do aluno exercem sobre os resultados escolares. Os estudos das relaçóes raciais na organização escolar, assim como a identificação de políticas raciais apropriadas para diminuição dessas diferenças aparecem como necessários. Nessa perspectiva, novas variáveis, como a composição racial da sala de aula ou da escola e as expectativas sobre os alunos por parte de mães e professores, passam a ser analisadas (Barbosa; Randall, 2004; Beltrão; Leite; Ferrão, 2002).

Os resultados desses estudos mostram um ordenamento já conhecido entre alunos de cor/raça distintas: os não-brancos possuem menor nível de proficiência, maior atraso escolar e maiores taxas de repetência. Revelam também variaçóes geográficas da influência da cor (Ferrão et al., 2001; Alves; Soares, 2002; Ferrão; Beltrão; Santos, 2002). A investigação empírica sobre eficácia escolar mostra que características e práticas escolares que influenciam positivamente o desempenho dos alunos e produzem eficácia escolar náo são distribuídas igualmente entre os estudantes de cor/raça distintas: influenciam muito mais os brancos do que os não-brancos. As melhorias afetam a diferença entre os alunos, mas no sentido de aumentá-las (Alves; Soares, 2002; Alves; Soares, 2003; Soares, 2004; Soares; Candian, 2007). Alves e Soares (2003) apontam duas explicaçóes para

${ }^{2}$ A cor do aluno é definida com base na autodeclaração. Assim, sempre que se referir a cor/raça do aluno, levar-se-á em conta que se trata da percepção do entrevistado. 
tal: que os negros não usufruem das melhorias da escola da mesma maneira que os brancos, por práticas e atitudes internas às escolas, ou que esses alunos não possuem pequenas vantagens iniciais que, inseridas em um contexto de melhorias, poderiam se potencializar. Em qualquer das direçôes, o problema da discriminação permanece.

Embora os termos "negros" ou "não-brancos" sejam comuns para indicar pessoas que se declaram "pretas" ou "pardas", a investigação sobre a contribuição dos fatores escolares no efeito da cor/raça do aluno indica que não faz mais sentido essa agregação. $\mathrm{O}$ diferencial de desempenho entre brancos e pardos é muito inferior àquele entre brancos e pretos. Além do mais, fatores escolares possuem efeitos diferenciados sobre pardos e pretos (Bonamino et al., 2002; Alves; Soares, 2002; Alves; Soares, 2003; Barbosa; Randall, 2004). Existem evidências de que a diferença de desempenho entre eles é menor quanto menor for o nível socioeconômico e cresça com o aumento tanto do nível socioeconômico do aluno como da escola. Isso significa que a influência da cor/raça e do nível socioeconômico não podem ser analisados de forma independentes. Essa evidência aponta para a necessidade de uma investigação sobre a interação entre nível socioeconômico e cor/raça (Alves; Soares, 2002; Alves; Soares, 2003).

A interação foi considerada em pesquisa realizada por Alves e Soares (2007) sobre os fatores associados ao risco de repetência dos alunos. Esse estudo mostrou que a interação entre cor/raça e capital econômico exerce uma influencia significativa. Um capital econômico maior pode ser um fator de proteção contra a repetência para os alunos que se declaram brancos, mas náo para os que se declaram pretos, indicando assim que o capital econômico possui um efeito diferenciado entre grupos raciais no que tange aos riscos de repetência. Como a repetência está associada ao desempenho escolar do aluno, é razoável acreditar que a interação tenha efeito também na proficiência do aluno.

A justificativa para a investigação da influência conjunta da cor/raça e dos capitais está na crença de que a desigualdade racial no Brasil não é um fenômeno meramente econômico. Famílias de cor/raça distintas possuem valores e práticas diferenciadas em relação à escolarização dos seus filhos. No mais, existem fatores das relaçóes raciais no espaço escolar, muito além daqueles captados pelo Saeb, que podem ser determinantes no sucesso escolar de uma criança.

A hipótese testada no presente artigo é de que não só o desempenho do aluno sofre influência conjunta da cor/raça e do nível socioeconômico como esse efeito varia segundo a escola frequentada. Ou seja, investiga-se se o efeito das oportunidades 
educacionais, representadas pelos recursos familiares sobre a proficiência do aluno, independe da cor/raça e da escola frequentada.

Até a conclusão da pesquisa, nenhum estudo sobre efeito-escola havia considerado a interação entre cor/raça e nível socioeconômico em sua modelagem; tampouco aqueles com foco na cor/raça do aluno haviam separado o índice de nível socioeconômico em várias dimensões. A contribuição à literatura existente foi investigar se faz sentido estatisticamente estudar a influência conjunta da cor/raça declarada pelo aluno e seu nível socioeconômico decomposto em quatro indicadores: de capital econômico, cultural, social familiar de convivência e de interação. A próxima seçáo apresenta as dimensóes do índice de nível socioeconômico comumente utilizadas, assim como uma proposta para a sua desagregação.

\section{NÍVEL SOCIOECONÔMICO}

O controle pela origem social do aluno nas pesquisas sobre efeito-escola é realizado, uma vez que o nível socioeconômico do estudante e de sua família é apontado como a variável explicativa mais importante do desempenho individual do aluno. Inexiste na literatura pesquisada uma forma única de cálculo do indicador do nível socioeconômico. Entretanto, três dimensóes principais são contempladas: a dos recursos econômicos - ou capital econômico da família; a dimensáo dos recursos educacionais, também denominados capital humano ou capital cultural; e, por fim, a dimensão das relaçóes familiares, ou capital social familiar.

\subsection{Dimensóes}

O capital econômico está relacionado à renda ou às condiçóes de moradia dos alunos. A forma mais comum de mediçáo consiste na agregação de itens dos questionários por meio de diferentes metodologias (análise fatorial, TRI, GOM), de forma a obter um único indicador. No questionário do Saeb não existe informação sobre a renda familiar, e assim a aplicação de tais questóes torna-se complicada, uma vez que a resposta é dada por crianças que não conhecem com exatidão essas informaçóes. A agregação é feita com base na investigação da presença de bens de consumo no domicílio do aluno, geralmente considerando o Critério Brasil (Ferrão et al., 2001; Alves; Soares, 2002; Alves; Soares, 2007). Como salientam Soares e Collares (2006), a reduçáo do indicador de nível socioeconômico apenas à dimensão da condição econômica da família é prejudicial para os estudos sobre as práticas escolares que poderiam ser desenvolvidas em parceria com a família. Ademais dos recursos econômicos, culturais e o envolvimento dos pais, os autores também apontam para a relevância de outros 
fatores familiares, como a organização da família, o clima emocional, e o estresse familiar. Esses fatores, entretanto, não são captados pelos questionários do Saeb.

A segunda dimensão trata da distribuição da educação entre os membros adultos de uma família e da presença de bens educacionais na residência. A escolaridade dos pais, em alguns casos, é analisada de forma separada como uma medida de capital cultural da família. Também faz parte desta dimensáo a investigação sobre a presença de livros, revistas de informação, etc., e sobre a frequência dos alunos a atividades culturais (cinema, teatro, shows de música, etc.). Essa dimensáo estaria fortemente relacionada com a primeira, uma vez que sem os recursos econômicos, seria impossível a aquisição de bens culturais em quantidades suficientes para influenciar o processo de escolarização do aluno (Soares; Collares, 2006).

A terceira dimensão é a do capital social. A importância do capital social dos alunos no desempenho escolar é apontada por Ferrão, Beltrão e Santos (2002a), e Barbosa e Fernandes (2003) e Soares e Collares (2006) ${ }^{3}$. O conceito de capital social foi desenvolvido por Bourdieu e posteriormente por James Coleman ${ }^{4}$. Para Coleman (1996), o capital social trata do conjunto de relaçóes sociais em que o indivíduo se encontra inserido e que o ajudam a atingir objetivos que, sem tais relaçóes, seriam inalcançáveis ou somente alcançáveis a um custo mais elevado. A noção de capital social possui na literatura diversas interpretaçóes. Aplicado à esfera educacional, tal conceito se refere à relaçáo casa-escola, notadamente à existência de um ambiente familiar favorável à educação e às melhorias no desempenho das crianças. Em suma, trata do interesse e da disponibilidade das famílias em acompanhar o processo de escolarização, incluindo tanto o tempo que os adultos dedicam às crianças e às conversas sobre a vida escolar como a existência de "espaços físicos e temporais que permitam a elas se dedicar exclusivamente aos estudos" (Ferrăo; Beltráo; Santos, 2002a) $)^{5}$. A seguir, apresenta-se a metodologia para a desagregaçáo do índice, assim como os itens do Saeb utilizados para a sua construçáo.

${ }^{3}$ A fim de evitar confusóes com as diversas interpretaçōes do conceito de capital social, os autores chamaram essa dimensão de "envolvimento dos pais".

${ }^{4}$ Segundo Aquino (2000), a diferença principal nas teorias de Bourdieu e Coleman é que para o primeiro o capital social é algo possuído por indivíduos, enquanto para o segundo o capital social "localiza-se não nos indivíduos, mas nas relaçóes entre eles" (p. 25).

${ }^{5}$ Os autores citam como variáveis indicativas de capital social: existência de um lugar calmo para estudar; número de pessoas que moram com o aluno e quem são; frequência das conversas entre os pais (ou responsáveis) e as crianças sobre livros, filmes programas de TV, vida escolar e outros assuntos; conversas com os amigos dos filhos e/ou com seus responsáveis; frequência da realizaçăo de atividades entre pais (ou responsáveis) e filhos, como ouvir música, almoçar ou jantar (Ferrão; Beltrão; Santos, 2002a). 


\subsection{Metodologia para a desagregação do nível socioeconômico}

Cada dimensão (econômica, cultural e social) pode ser resumida em índices construídos com base nos itens retirados dos questionários contextuais do Saeb. Buscou-se utilizar itens que, em conjunto, captem as condiçóes econômicas, familiares e sociais nas quais o estudante está inserido; embora não se possa estabelecer relação direta desses com os resultados escolares dos alunos, aparecem na literatura como tendo efeitos importantes. Dessa forma, o índice de capital econômico abrange a dimensão dos recursos econômicos, o índice de capital cultural representa a dotação de bens educacionais e das atividades culturais realizadas pelo estudante, e por fim o índice de capital social familiar representa a convivência entre alunos e pais ou responsáveis e a sua intervenção nas atividades escolares.

No caso particular do capital social, optou-se por denominá-la de "capital social familiar", pois os itens se referem mais a práticas intrafamiliares de convivência entre adultos e crianças do que a práticas voltadas para a escolarização em si; o termo social é mantido na medida em que expressa redes de interaçôes no interior da família. A dimensáo do capital social foi desagregada em dois indicadores: de capital familiar de convivência e de capital familiar de intervenção. Isto porque a teoria de que um maior tempo dispensado às crianças por parte dos adultos pudesse refletir uma proximidade destes na vida escolar daquelas não pôde ser verificada pela metodologia empregada, como se verá adiante.

\subsubsection{Capital econômico}

Os questionários do Saeb não apresentam informaçōes sobre renda domiciliar: o capital econômico é captado por meio de um bloco de perguntas que realizam um levantamento do quantitativo de certos bens na residência do aluno. Esse levantamento é feito com base no Critério $\mathrm{Brasil}^{6}$ e os itens investigados são: televisáo em cores, rádio, videocassete, banheiros, quartos, geladeira, freezer (junto ou separado da geladeira), máquina de lavar, aspirador de pó, automóvel/carro, computador com internet, computador sem internet, eletricidade, água encanada e empregada doméstica. Para alguns itens em que o Inep considera que a quantidade faz diferença ${ }^{7}$, as respostas são categóricas e ordenadas. Para os demais, a resposta é binária. Essa metodologia é ideal para contornar dificuldades na obtençâo de informaçóes confráveis

${ }^{6} \mathrm{O}$ Critério de Classificação Econômica Brasil é utilizado em pesquisas de mercado para estimar o poder de compra das pessoas e famílias urbanas, com divisão exclusivamente de classes econômicas e năo sociais.

${ }^{7}$ Televisăo em cores, rádio, banheiro, quartos, automóvel e empregada doméstica. 
sobre renda, ainda mais quando os questionários são aplicados a crianças que muitas vezes a desconhecem. Optou-se por um índice que permita relacionar bens de consumo a recursos econômicos da família, utilizando-se dados da PNAD.

Uma vez que a maioria dos itens investigados pelo Saeb, com exceção de videocassete, aspirador de pó, automóvel e empregada mensalista, também é investigada pela PNAD nos questionários de domicílios, e que a PNAD possui informaçáo sobre a renda domiciliar, os itens do Saeb compatíveis com a PNAD foram utilizados como variáveis de uma regressão linear múltipla para estimativa da renda domiciliar per capita (na escala log) do domicílio. $O$ ano da PNAD utilizado foi o de 2003 - o mesmo do Saeb - e foram estimadas duas regressôes: uma para cada amostra de crianças que frequentavam a escola na quarta e oitava série do ensino fundamental. Além dos itens apresentados no quadro 1, também foi incluída a variável de densidade do domicílio (número de quartos dividido pelo número de moradores).

Quadro 1 - Variáveis utilizadas no cálculo do capital econômico

\begin{tabular}{|c|c|c|}
\hline \multicolumn{3}{|c|}{ Variáveis } \\
\hline $\begin{array}{l}\text { Q.6 Televisão em cores } \\
\text { Q.7 Rádio } \\
\text { Q.11 Geladeira } \\
\text { Q.12/Q.13 Freezer } \\
\text { Q.14 Máquina de Lavar } \\
\text { Q.17 Computador com internet } \\
\text { Q.18 Computador sem internet } \\
\text { Q.20 Eletricidade } \\
\text { Q.21 Água encanada }\end{array}$ & \begin{tabular}{|l|} 
Binária \\
Binária \\
Binária \\
Binária \\
Binária \\
Binária \\
Binária \\
Binária \\
Binária \\
\end{tabular} & $\begin{array}{l}\text { Valores: } 1 \text { se existir mais de um } \\
\text { item na casa e } 0 \text { se não existir } \\
\text { nenhum item }\end{array}$ \\
\hline Q.9 Número de Banheiros & Categórica & $\begin{array}{l}\text { - Não tem } \\
1 \text { - Um } \\
2 \text { - Dois } \\
3 \text { - Três ou mais } \\
\end{array}$ \\
\hline Q.10 Número de Quartos & Categórica & $\begin{array}{l}0 \text { - Não tem } \\
1 \text { - Um } \\
2 \text { - Dois } \\
3 \text { - Três ou mais }\end{array}$ \\
\hline Q.10/Q.23 Densidade & Contínua & \\
\hline
\end{tabular}


Como as questóes referentes a cada item não são especificadas da mesma forma nas duas bases, algumas transformaçóes nas variáveis foram necessárias ${ }^{8}$. Os resultados das regressões estão no anexo; todas apresentam um alto $\mathrm{R}^{2}$, e todos os coeficientes são significativos. Os coeficientes foram aplicados aos dados do Saeb para estimar o nível de capital econômico dos alunos.

\subsubsection{Capital cultural, bens educacionais e capital social}

\subsubsection{Técnica GOM}

Os índices da segunda e terceira dimensóes foram construídos por meio da técnica GOM - Grade of Membership (Grau de Pertencimento). A ideia por trás da análise GOM é simples. Parte-se da premissa de que com base na resposta de um aluno a uma variável do Saeb é possível classificá-lo em duas situaçôes extremas (perfis) $K^{\prime}$ : uma primeira na qual ele possui todas as características consideradas ideais para alcançar bom rendimento na escola, e outra quando não possui nenhuma. O conjunto de respostas do aluno pertencente ao perfil ideal é separado do conjunto de resposta de outro que pertence ao perfil oposto. Na prática, sabe-se que a alocação dos alunos aos conjuntos é ambígua dado que os estudantes podem apresentar características dos dois conjuntos, e que esses conjuntos náo possuem contornos bem definidos.

A técnica GOM permite resolver essas ambiguidades. Por intermédio de um modelo de probabilidade multinomial, estimam-se dois parâmetros: o primeiro que determina o grau de pertencimento de cada aluno a um perfil extremo, e o segundo que define as características desses perfis. Para uma descrição da técnica, e sua aplicação aos dados do Saeb, ver Beltrão, Leite e Ferrão (2002). Segundo os autores, a técnica é eficiente e possui várias vantagens, apesar de ainda pouco utilizada na análise de dados nacionais. Dentre as vantagens, além da principal que é a quantificação das ambiguidades na alocaçáo dos elementos aos conjuntos, os autores

${ }^{8}$ Para os itens que apresentavam várias categorias, a presença do item foi considerada quando o aluno declarou a existência de um ou mais em sua residência. Considerou-se a presença do item "Freezer", quando o aluno declarou haver em sua casa freezer junto ou separado da geladeira. Para as variáveis: "Número de quartos" e "Número de banheiros" a categoria "três ou mais" foi substituída pelo número médio de quartos e banheiros, obtido para o conjunto de domicílios que na PNAD tinham três ou mais quartos ou banheiros. As perguntas sobre a posse desses bens são as mesmas para todas as séries.

${ }^{9}$ A técnica pode ser utilizada por mais de dois perfis. A opçáo por dois perfis neste trabalho foi feita para a produção de uma escala única. 
citam a possibilidade de redução da dimensionalidade dos dados, a não-necessidade de um conhecimento prévio dos conjuntos, e por fim a possibilidade de contornar problemas com dados faltantes, evitando assim perda de observaçóes. Isso é possível adotando os dados omissos como uma categoria de resposta.

$O$ grau de pertencimento de um aluno específico $i$ a um perfil $K$ é dado pela estatística $g_{k}$ que mede a associação do aluno ao perfil em questão; $g_{k}$ mede quanto dos $J$ atributos de um perfil extremo um determinado aluno $i$ possui. O grau de pertinência $g_{k}$ é uma variável contínua no intervalo [0;1]. Se $g_{k}$ assumir o valor zero o aluno não pertence ao conjunto, já se $g_{k}$ for igual a unidade, significa que o aluno pertence exclusivamente ao conjunto considerado. Nesse caso específico onde temos apenas dois conjuntos, $g_{k}$ pode ser considerada a "distância" na qual o aluno $i$ se encontra entre os dois perfis. Se todos os valores de $g_{k}$ forem iguais a 0 ou 1 , teremos uma classificação bem definida.

O grau de pertinência possui as seguintes propriedades:

$$
\begin{aligned}
& g_{i k} \geq 0, \forall \mathrm{i} \text { e k; } \\
& \sum_{\mathrm{k}=1}^{\mathrm{K}} \mathrm{g}_{\mathrm{ik}}=1, \forall \mathrm{i} .
\end{aligned}
$$

Os parâmetros que permitem definir as características dos conjuntos são as estimativas $\lambda_{k}$ que representam a probabilidade de resposta $l$ da variável $j$ por parte de um aluno $i$ com perfil $K$. Dessa forma, relacionam-se os perfis extremos e as categorias de resposta das variáveis utilizadas. Quando para uma dada variável, $\lambda_{k}$ assumir o valor 0 ou 1 para todos os perfis, entáo os conjuntos são disjuntos e não possuem respostas em comum.

O parâmetro utilizado na regressão multinível é $g_{i k}$. Os parâmetros foram estimados com o software GOM 3.0 - versão DOS. Ao optar-se por dois perfis, o programa fornece dois parâmetros $g_{k}$ complementares, ou seja, um grau de pertencimento do aluno a um perfil mais adequado para uma boa escolarizaçáo e ao oposto. Cabe ao pesquisador identificar qual dos perfis é o mais positivo e optar assim por um dos dois parâmetros. As variáveis retiradas do Saeb, assim como as categorias de resposta correspondentes, seráo especificadas a seguir para a dimensáo do capital cultural/bens educacionais e do capital social familiar. Como as categorias de resposta das variáveis do Saeb se referem à frequência de realizaçáo de determinadas práticas consideradas positivas para a escolarização do aluno, estima-se que o perfil ideal seja aquele em que a frequência de tais práticas seja a maior possível. 


\subsubsection{Capital cultural e bens educacionais}

Quadro 2 - Variáveis utilizadas no cálculo do capital cultural

\begin{tabular}{|c|c|c|}
\hline \multicolumn{3}{|c|}{ Variáveis } \\
\hline Q.18 Quantidade de livros em casa & Categórica & $\begin{array}{l}\text { 1- Mais de } 100 \text { Livros } \\
2 \text { - } 21 \text { a } 100 \text { livros } \\
3 \text { - } 1 \text { a } 20 \text { livros } \\
4 \text { - Nenhum } \\
5 \text { - Omissos }\end{array}$ \\
\hline Q.23/Q.27 Mora com pai ou mãe & Categórica & $\begin{array}{l}\text { 1- Sim } \\
\text { 2- Năo } \\
\text { 3- Não, moro com responsável } \\
\text { 4-Omissos }\end{array}$ \\
\hline Q.24/Q.28 Māe ou pai analfabeto & Categórica & $\begin{array}{l}\text { 1- Sim } \\
2 \text { - Não } \\
3 \text { - Omisso/nāo sei }\end{array}$ \\
\hline Q.26/Q.30 Vê a mãe ou pai lendo? & Categórica & $\begin{array}{l}\text { 1- Sim } \\
2 \text { - Não } \\
3 \text { - Omisso/não sei }\end{array}$ \\
\hline Q.31 Pessoa que acompanha os estudos mais de perto & Categórica & $\begin{array}{l}\text { 1- Minha mãe } \\
2 \text { - Outra mulher da minha familia } \\
3 \text { - Meu pai } \\
4 \text { - Outro homem da minha família } \\
5 \text { - Empregada } \\
6 \text { - Ninguém } \\
7 \text { - Omisso } \\
\end{array}$ \\
\hline $\begin{array}{l}\text { Q.25/Q.29 Escolaridade do pai e da măe } \\
\text { Q.32 Escolaridade da pessoa que acompanha os estudos } \\
\text { mais de perto }\end{array}$ & $\begin{array}{l}\text { Categórica } \\
\text { Categórica }\end{array}$ & $\begin{array}{l}1 \text { - Completou a faculdade } \\
2 \text { - Começou, mas não completou a } \\
\text { faculdade } \\
3 \text { - Completou o ensino médio } \\
4 \text { - Não completou o ensino médio } \\
5 \text { - Completou a } 8^{\text {a }} \text { série } \\
6 \text { - Não completou a } 8^{a} \text { série } \\
7 \text { - Completou a } 4^{\text {a }} \text { série } \\
8 \text { - Não completou a 4a série } \\
9 \text { - Nunca estudou } \\
10 \text { - Omissos/não sei }\end{array}$ \\
\hline $\begin{array}{l}\text { Q.35 Lê revistas em quadrinhos } \\
\text { Q.36 Lê revistas de informação geral } \\
\text { Q.37 Lê livros de literatura, como romance, ficção, etc. } \\
\text { Q.38 Lê jornais } \\
\text { Q.39 Lê ou faz consulta na biblioteca da escola } \\
\text { Q.40 Lê ou faz consulta na biblioteca fora da escola }\end{array}$ & $\begin{array}{l}\text { Categórica } \\
\text { Categórica } \\
\text { Categórica } \\
\text { Categórica } \\
\text { Categórica } \\
\text { Categórica }\end{array}$ & $\begin{array}{l}1 \text { - Sempre ou quase sempre } \\
2 \text { - De vez em quando } \\
\text { - Nunca ou quase nunca } \\
4 \text { - Omissos/não sei }\end{array}$ \\
\hline Q.33 Chega jornal em casa para ler & Categórica & $\begin{array}{l}\text { 1-Sim, todos os dias } \\
2 \text { - Sim, pelo menos uma vez por semana } \\
3 \text { - Não } \\
4 \text { - Năo sei }\end{array}$ \\
\hline $\begin{array}{l}\text { Q.41 Costuma ir ao cinema } \\
\text { Q.42 Costuma ir ao teatro } \\
\text { Q.43 Costuma ir a shows de música } \\
\text { Q.44 Costuma ir a exposições }\end{array}$ & $\begin{array}{l}\text { Categórica } \\
\text { Categórica } \\
\text { Categórica } \\
\text { Categórica } \\
\end{array}$ & $\begin{array}{l}1 \text { - Sempre ou quase sempre } \\
2 \text { - De vez em quando } \\
3 \text { - Nunca ou quase nunca } \\
4 \text { - Omissos/näo sei }\end{array}$ \\
\hline $\begin{array}{l}\text { Q.45 Tempo vendo TV em dia de aula } \\
\text { Q.46 Tempo estudando ou fazendo liçóes de casa }\end{array}$ & $\begin{array}{l}\text { Categórica } \\
\text { Categórica }\end{array}$ & $\begin{array}{l}1 \text { - } 1 \text { hora ou menos } \\
2-2 \text { horas } \\
3-3 \text { horas } \\
4-4 \text { horas ou mais } \\
5 \text { - Não vejo televisão } \\
6 \text { - Omissos }\end{array}$ \\
\hline Q.47 Tempo fazendo trabalhos domésticos & Categórica & $\begin{array}{l}1 \text { - Não faço trabalho domésticos } \\
2 \text { - } 1 \text { hora ou menos } \\
3 \text { - } 2 \text { horas } \\
4-3 \text { horas } \\
5 \text { - } 4 \text { horas ou mais } \\
6 \text { - Omissos }\end{array}$ \\
\hline Q.48 Tempo que trabalha fora de casa em dia de aula & Categórica & $\begin{array}{l}1 \text { - Não trabalho fora de casa } \\
2 \text { - Até } 4 \text { horas } \\
3 \text { - De } 5 \text { a } 6 \text { horas } \\
4 \text { - Mais de } 6 \text { horas } \\
5 \text { - Omissos }\end{array}$ \\
\hline
\end{tabular}


No caso específico do capital social familiar, temos dois indicadores em vez de um. O primeiro indicador se refere ao tempo dispensado pelos pais aos filhos, ou seja, trata da frequência com que os pais almoçam, jantam, ouvem música, conversam com os filhos e os ajudam no dever de casa, denominado "capital social familiar de convivência". O segundo indicador, denominado "capital social familiar de intervençāo", trata de açōes de escolarização mais diretas, como cobranças (para náo faltar, para tirar notas boas) e frequência nas reuniôes de pais. A utilizaçáo de dois indicadores em vez de um deu-se pela impossibilidade de identificação de um perfil considerado ideal quando se juntaram inicialmente todas as variáveis de relaçóes intrafamiliares. Muitas crianças que responderam que passam um tempo considerável com seus pais também declararam que eles não cobram delas suas tarefas escolares e não vão a reunióes da escola com frequência. Além do mais, cobranças frequentes podem ocorrer principalmente quando o aluno está mal na escola.

\subsubsection{Capital social familiar (convivência)}

Quadro 3 - Variáveis utilizadas no cálculo do capital social familiar de convivência

\begin{tabular}{|l|l|l|}
\hline \multicolumn{2}{|c|}{ Variáveis } \\
\hline Q.47 Pais almoçam ou jantam com os filhos & Categórica & \\
Q.48 Pais ouvem música com os filhos & Categórica & \\
Q.49 Pais conversam sobre livros & Categórica & 1 - Sempre ou quase sempre \\
Q.50 Pais conversam sobre filmes & Categórica & 2 - De vez em quando \\
Q.51 Pais conversam sobre programas & Categórica & 3 - Nunca ou quase nunca \\
Q.52 Pais conversam com os amigos & Categórica & 4 - Omissos/não sei \\
Q.53 Pais conversam sobre o que acontece na escola & Categórica & \\
Q.54 Pais ou responsáveis ajudam no dever de casa & Categórica & \\
\hline
\end{tabular}

\subsubsection{Capital social familiar (intervençäo)}

Quadro 4 - Variáveis utilizadas no cálculo de capital social familiar de intervenção

\begin{tabular}{|l|l|l|}
\hline \multicolumn{3}{|c|}{ Variáveis } \\
\hline Q.55 Pais cobram se fez o dever de casa & Categórica & 1 - Sempre ou quase sempre \\
Q.56 Pais falam para não faltar às aulas & Categórica & 2- De vez em quando \\
Q.57 Pais falam para você tirar notas boas & Categórica & 3 - Nunca ou quase nunca \\
Q.58 Frequência dos pais a reunião na escola & Categórica & 4-Omissos/não sei \\
\hline
\end{tabular}




\section{APLICAÇÃo}

Para testar os índices, foram estimados três modelos hierárquicos para explicar o desempenho em matemática de alunos da $4^{\mathrm{a}}$ e $8^{\mathrm{a}}$ séries de uma amostra de escolas brasileiras participantes do Saeb em 2003. As regressôes foram estimadas com a ajuda do software HLM 5.02. O objetivo foi o de avaliar os efeitos das características individuais do aluno e da escola no desempenho médio dos alunos nas duas séries, assim como a variabilidade entre as escolas da amostra. A escolha por matemática deu-se, uma vez em que se acredita que o aprendizado dessa matéria está muito mais relacionado ao ambiente escolar, ao contrário do de línguas que estaria mais relacionado à origem familiar.

Todos os modelos consideraram, além do nível socioeconômico do aluno, o sexo, sua situação no processo de escolarização (por meio da sua situação de repetência, de defasagem, e adequação idade/série) e seu nível de recursos familiares em relaçáo à média da escola, variáveis contextuais como o nível médio de capital econômico, cultural e social familiar da escola e o efeito da rede de ensino. Esse procedimento é empregado, uma vez que se assume que a alocação dos indivíduos na escola não é feita de forma aleatória, com alunos com condiçōes econômicas semelhantes frequentando as mesmas escolas. Ademais, estudantes inseridos em salas de aulas com colegas motivados tendem a obter resultados melhores, independentemente da sua própria motivação, é o chamado "efeito dos pares" (Soares; César, 2001).

Os modelos e seus resultados estão especificados no anexo. As variáveis finais dos modelos foram encontradas, retirando-se aquelas com maior $\mathrm{p}$-valor. $\mathrm{O}$ primeiro modelo, contendo as variáveis descritas anteriormente e chamado de modelo básico, foi feito sem acréscimo da variável de cor/raça; o segundo incorpora essa variável desagregada entre brancos, pardos e pretos; e o terceiro possui também os termos de interação entre cor/raça e capitais calculados. Como o objetivo era avaliar o impacto das diferentes dimensóes dos recursos familiares, não foram incorporadas variáveis escolares usualmente utilizadas em pesquisas sobre os fatores escolares promotores de eficácia e equidade (infraestrutura, características docentes, etc.). Entretanto, a proposta aqui é incorporar este índice desagregado em estudos futuros.

\section{RESULTADOS}

Para todos os modelos em que as variáveis de interaçâo foram significativas, encontraram-se os sinais esperados para a influência do sexo e a situação do aluno, comumente apontados na literatura (homens possuem maior desempenho em matemática, assim como uma trajetória irregular no processo o diminui). Em relaçáo 
aos recursos familiares, apenas o capital de convivência apresentou efeito contrário ao esperado: um acréscimo no nível desse capital possuído pelo aluno em relação à média da escola diminui o seu desempenho. $O$ capital de intervenção não foi significativo para a $8^{a}$ série, sinalizando que para esse nível a intervenção mais direta dos pais no processo de escolarização talvez não seja tão importante como na $4^{\mathrm{a}}$ série.

Os capitais econômicos e culturais médios das escolas possuem impactos significativos no desempenho do estudante, assim como a rede na qual ele está inserido. Isso indica que quanto maior o nível de capital econômico e cultural no ambiente dos alunos maior será o seu desempenho. O chamado "efeito dos pares" ocorre principalmente na $8^{a}$ série em que o efeito do nível de capital cultural médio da escola no desempenho do estudante chega a dobrar em relação à $4^{a}$ série. Conforme já apontado pela literatura, o capital cultural é o que possui maior impacto no desempenho do aluno. Em todos os modelos para os quais as variáveis se revelaram significativas, o capital de intervenção do aluno e o capital de convivência apresentaram efeito maior do que o capital econômico, embora o mesmo náo ocorra com a média escolar. Isso indica que a proficiência do aluno em matemática pode estar relacionada muito mais às práticas familiares do que ao seu nível econômico, conforme mencionado por Lahire (1997).

Ainda que a magnitude dos efeitos dos níveis de capitais individuais do aluno em relação à média da escola seja baixa em comparação com o próprio nível médio da escola, a significância dos termos aleatórios ${ }^{10}$ indica que existe um certo grau de diferenciação nas escolas da amostra em relação aos níveis de capitais dos alunos, mesmo quando estudantes com recursos familiares semelhantes frequentam a mesma escola.

Os resultados dos modelos com as variáveis de cor/raça apontam que na $4^{a}$ série brancos e pardos não apresentam diferenças significativas (do ponto de vista estatístico) no desempenho médio; essa diferença pode estar muito mais relacionada às diferenças nos indicadores escolares do que à cor/raça em si. Já a diferença no desempenho médio entre brancos e pretos, depois de efetuados os controles, é de cerca de 12 pontos na $4^{a}$ série. Existe uma diferença significativa no desempenho médio entre alunos brancos e pretos, porém, nenhuma interação entre a cor/raça e o nível de recursos familiares.

${ }^{10}$ Nos modelos hierárquicos, os termos aleatórios se referem a parte da variaçâo do desempenho dos alunos que não pode ser explicada pela equação no nível a que se refere. Ou seja, quando os termos aleatórios são significativos, isso indica que existe um componente referente à escola que não é captado pela equação do alunos. 
As variáveis de interação entre cor/raça e os capitais só se revelaram significativos na $8^{a}$ série. Os resultados obtidos indicam que existe um desempenho médio distinto e ordenado entre brancos, pardos e pretos, assim como uma interaçáo entre o nível de capital econômico e pretos, capital econômico e pardos e capital cultural e pardos. Quanto maior o nível do capital econômico em relação à média da escola, maior será o desempenho dos alunos pretos e pardos. O efeito é praticamente o mesmo para os dois grupos. Em relação ao efeito do capital cultural para os pardos, embora o termo simples revele um efeito considerável do nível de capital cultural no desempenho em matemática dos alunos, o termo de interação entre pardos e capital cultural possui um sinal negativo, indicando que para cada aumento no nível desse capital em relaçáo à média da escola o desempenho dos pardos é diminuído em relação ao dos brancos.

Os termos aleatórios indicam que o impacto do nível de recursos familiares possuído pelo aluno em relaçáo à média da escola varia de acordo com a escola frequentada, assim como o efeito das interaçóes entre pardos e capital econômico, pretos e capital econômico para as duas séries avaliadas, e capital cultural e pardos para a $8^{\mathrm{a}}$ série.

\subsection{Comparação entre os modelos}

A tabela 1 apresenta os efeitos-escola encontrados para cada série e modelo, segundo a metodologia de cálculo. No modelo básico o efeito-escola calculado é maior na $8^{\mathrm{a}}$ série do que na $4^{\mathrm{a}}$ : $26,0 \%$ da variação no desempenho médio do aluno em matemática é explicada pela variação entre as escolas nesta série e $27,5 \%$ naquela. Já no modelo de cor/raça, nota-se que com a introdução do termo cor/raça o efeito-escola praticamente não se alterou: passou de $26,0 \%$ no modelo básico para $25,7 \%$ neste, na $4^{a}$ série, e de $27,6 \%$ para $27,4 \%$ na $8^{a}$. O efeito-escola no modelo com interação para a $8^{a}$ série é maior do que os demais: $28,6 \%$ da variação total do desempenho são explicados por variações entre as escolas. Para a 4a, em razão da não significância dos termos de interação, o efeito-escola é igual ao do modelo com as variáveis de cor/raça. 
Tabela 1 - Cálculo do efeito-escola por série, metodologia de cálculo e modelo

\begin{tabular}{l|c|c|c}
\hline \multicolumn{1}{c|}{ Série } & $\begin{array}{c}\text { Modelo } \\
\text { básico } \\
\%\end{array}$ & $\begin{array}{c}\text { Modelo } \\
\text { cor/raça } \\
\%\end{array}$ & $\begin{array}{c}\text { Modelo com } \\
\text { interação } \\
\%\end{array}$ \\
\hline 4a Série & & & \\
$\quad$ Considerando as variações nos efeitos dos capitais & 26,0 & 25,7 & 25,7 \\
Coeficiente de correlação intraescolar & 16,7 & 16,7 & 16,7 \\
\hline 8a Série & & & \\
$\quad$ Considerando as variações nos efeitos dos capitais & 27,6 & 27,4 & 28,6 \\
$\quad$ Coeficiente de correlação intraescolar & 13,7 & 13,6 & 15,4 \\
\hline
\end{tabular}

A tabela 2 apresenta a análise de deviance para a $8^{a}$ série. A diferença entre as deviance de dois modelos possui distribuição chi-quadrado com graus de liberdade iguais à diferença no número de parâmetros entre os modelos analisados. Os resultados indicam que tanto o acréscimo da variável de cor/raça ao modelo básico quanto dos termos de interação ao modelo de cor/raça (na $8^{\mathrm{a}}$ série) aumentam significativamente a capacidade de explicação do modelo. A análise das deviances dos modelos indica que para a $8^{\mathrm{a}}$ série, única na qual esses termos foram significativos, as variáveis de interação melhoram significativamente a capacidade de explicação do modelo. Com a introdução da interação, a dummy para pardos passou a ser significativa, indicando que quando levadas em consideração as interações, não só o desempenho médio dos pardos é inferior aos dos brancos como existem diferenças no grau de discriminação entre esses dois grupos. No mais, o efeito da dummy para pretos passou a ser maior do que o efeito do histórico de repetência.

Tabela 2 - Análise de deviance (ANODE)

\begin{tabular}{c|lcccc}
\hline Série & \multicolumn{1}{|c}{ Modelo } & $\boldsymbol{p}$ & $\begin{array}{c}\text { Chi- } \\
\text { Quadrado }\end{array}$ & df & p-valor \\
\hline \multirow{3}{*}{ 4a Série } & Modelo Básico X Modelo Cor/Raça & 16 & 437 & 0 & 0,000 \\
& Modelo Cor/Raça X Modelo com Interação & - & - & - & - \\
& Modelo com Interação X Modelo Básico & - & - & - & - \\
\hline \multirow{3}{*}{ 4a Série } & Modelo Básico X Modelo Cor/Raça & 11 & 382 & 0 & 0,000 \\
& Modelo Cor/Raça X Modelo com Interação & 11 & 3013 & 18 & 0,000 \\
& Modelo com Interação X Modelo Básico & 29 & 3395 & 18 & 0,000 \\
\hline
\end{tabular}




\section{CONCLUSÃo}

A análise aqui efetuada leva à constatação de uma heterogeneidade conhecida entre as escolas públicas da amostra visto que, com os controles realizados, a maior parte do desempenho médio da escola onde o aluno está inserido é explicada pelo desempenho médio total das escolas públicas. Parte dessa variaçáo pode ser explicada por variaçóes regionais que não foram incorporadas na análise, mas que podem ser exploradas futuramente.

$\mathrm{Na} 4^{\mathrm{a}}$ série, não existem diferenças significativas no efeito do desempenho médio entre brancos e pardos, mas os estudantes pretos estão em situação de desvantagem em relação a esses alunos, e essa desvantagem ocorre independentemente do nível de recursos familiares possuídos. $\mathrm{Na} 8^{\mathrm{a}}$ série do ensino fundamental, as diferenças de desempenho médio entre pardos e brancos passam a ser significativas, e o impacto do nível de capital econômico (que parece compensar os efeitos da cor/raça) difere entre os três grupos, mesmo que em grau pequeno. Pardos e pretos sofrem impactos parecidos segundo o nível de capital econômico possuído, porém alunos pardos possuem impacto diferenciado em relação ao seu nível de capital cultural principalmente.

O nível de capital cultural possui um efeito importante sobre o desempenho dos estudantes pardos, mas um maior nível destes em relação à média da escola não anula o efeito da cor/raça. Cabe indagar se náo se obteria o mesmo efeito caso o número de pretos fosse maior na mesma série.

Do ponto de vista das pesquisas empíricas, pelo menos no que tange aos estudos sobre efeito-escola e cor/raça no Brasil, faz sentido a desagregaçáo do nível socioeconômico, uma vez que cada uma das dimensóes apresentadas possui efeito diferenciado em cada grupo e em cada série. A agregaçáo em um único indicador de nível socioeconômico pode servir como controle, mas a análise das diferentes dimensóes dos recursos familiares pode ser importante na explicação do desempenho dos alunos em matemática.

Em relação às avaliaçôes de larga escala, a pesquisa aponta para pelo menos duas contribuiçôes ao questionário do Saeb: em primeiro lugar, nota-se que cada vez mais é preciso explorar as características familiares dos alunos entrevistados, não apenas do ponto de vista de posse de bens, econômicos ou educacionais, mas principalmente no que se refere às práticas familiares, clima e transferência de capitais. Em segundo lugar, destaca-se a importância de estudar e captar práticas internas das escolas para além da infraestrutura e gestão. Questóes relacionadas às práticas dentro da sala de aula e ao processo ensino-aprendizagem contribuiriam para aprofundar 
os estudos sobre efeito-escola. Alguns aspectos das relaçóes professores-alunos podem ser abordados, como violência, discriminação e até mesmo expectativas em relaçáo à escola, a exemplo do que é investigado no questionário do Enem.

Se o objetivo é estudar a fundo as práticas escolares que podem aumentar o desempenho médio da escola e reduzir o impacto do nível socioeconômico, e principalmente da cor/raça do aluno, é preciso levar em consideração que esses efeitos não ocorrem de forma independente e variam segundo a escola frequentada.

\section{REFERÊNCIAS BIBLIOGRÁFICAS}

ALVES, M. T. G.; SOARES, J. F. Raça e desempenho escolar: as evidências do Sistema Nacional de Avaliação da Educação Básica Saeb. In: ENCONTRO ANUAL DA ANPOCS, 26. 2002. Anais... Caxambu, ANPOCS, 2002.

. Desigualdades raciais no Sistema Brasileiro de Educação Básica. Educação $e$ Pesquisa, São Paulo, v. 29, n. 1, p. 147-165, jan./ jun. 2003.

As Pesquisas sobre o efeito das escolas: contribuições metodológicas para a Sociologia da Educação. Sociedade e Estado, Brasília, v. 22, n. 2, p. 435-473, maio/ago. 2007.

AQUINO, J. A. de. As Teorias da ação social de Coleman e Bourdieu. Humanidades e Ciências Sociais, v. 2, n. 2, 2000.

BARBOSA, M. E. F.; FERNANDES, C. A Escola brasileira faz diferença? Uma investigação dos efeitos da escola na proficiência em matemática dos alunos da $4^{a}$ série. In: FRANCO, C. (Org.). Promoção, ciclos e avaliação educacional. Curitiba: ArtMed, 2001.

- O Efeito-escola e a mudança: dá para mudar? Evidências da investigação brasileira. Revista Electrónica Iberoamericana sobre Calidad, Eficacia y Cambio en Educación, v. 1, n. 1, 2003. Disponível em: <http://www. ice.deusto.es/RINACE/reice/vol1n1/Reo_ FerraoyFernandes.htm>. Acesso em: $19 \mathrm{fev}$. 2008.

BARBOSA, M.L.de O.; RANDALL, L. OImpacto da cor sobre o desempenho dos estudantes segundo as características da famllia e o contexto da escola. 2004. Disponivel em: <http://brazilink. org/education\%20papers/Barbosa\%20\&\%20 Randall.pdf>. Acesso em: jul. 2008.

BELTRÃO, K. I.; LEITE, I. C.; FERRÃO, M. E. O Ambiente escolar no desempenho acadêmico do aluno: criação de uma escola a partir do Saeb-99. Estudos em Avaliação Educacional, São Paulo, n. 26, p. 75-91, jul./dez. 2002.

BONAMINO, Alicia et al. Eficácia e equidade na educação básica brasileira: evidências baseadas nos dados do Saeb 2001. Rio de Janeiro: PUCRio, Laboratório de Avaliação da Educação, 2002.

BORDIEU, Pierre. A Reprodução. Rio de Janeiro: Francisco Alves, 1992.

COLEMAN, J. S. et al. Equality of educational opportunity. Washington. Dept. of Health, Education and Welfare. 1996.

FERRÃO, M. E. Introdução aos modelos de regressão multinivel em educação. Campinas: Komedi, 2003.

FERRÃO, M. E.; BELTRÃO, K. I.; SANTOS, D. P. Correção da defasagem escolar: efeito das políticas de não-repetência no desempenho acadêmico dos alunos da $4^{\text {a }}$ série: modelagem multinível: relatório técnico. Brasília: MEC/Inep, $2002 a$.

. Política de não-repetência e a qualidade da educação: evidências obtidas a partir da modelagem dos dados da $4^{a}$ série do Saeb-99. Estudos em Avaliação Educacional, 
São Paulo, n. 26, p. 47-73, jul./dez. 2002.

FERRÃO, M. E. et al. O Saeb - Sistema Nacional de Avaliação da Educação Básica: objetivos, características e contribuições na investigação da escola eficaz. Revista Brasileira de Estudos da População, Rio de Janeiro, v. 18, n. 1/2, jan./dez. 2001.

LAHIRE, B. Sucesso escolar nos meios populares: as razões do improvável. São Paulo: Ática, 1997. (Fundamentos).

SOARES, J. F. Qualidade e equidade na educação básica brasileira: a evidência do Saeb-2001. Archivos Analíticos de Políticas Educativas, v. 12, n. 38, 2004.

SOARES, J. F.; CANDIAN, J. F. O Efeito da escola básica brasileira: as evidências do PISA e do
Saeb. Revista Contemporânea de Educação. Rio de Janeiro, n. 4, 2007.

SOARES, J. F.; CÉSAR, C. C. Desigualdades acadêmicas induzidas pelo contexto escolar. Revista Brasileira de Estudos de População, Rio de Janeiro, v. 18, n. 1/2, jan./ dez. 2001.

SOARES, J. F.; COLLARES, A. C. M. Recursos familiares e o desempenho cognitivo dos alunos do ensino básico brasileiro. DADOS: Revista de Ciências Sociais, Rio de Janeiro, $v$. 49, n. 3, p. 615-481, 2006.

SOARES, J. F. et al. Escola eficaz: um estudo de caso em três escolas da rede pública de ensino do Estado de Minas Gerais. Belo Horizonte: UFMG; Ford Foundation, 2002. 


\section{Anexo A - Resultado das regressões - Capital Econômico}

Coeficientes estimados para a $4^{\mathrm{a}}$ série

\begin{tabular}{|c|c|c|c|c|c|c|}
\hline $\begin{array}{l}\text { Source } \\
\text { Model } \\
\text { Residual }\end{array}$ & $\begin{array}{c}\text { SS } \\
176470,73 \\
6977,46\end{array}$ & $\begin{array}{c}\text { df } \\
12 \\
7642\end{array}$ & $\begin{array}{c}\text { MS } \\
14705,8 \\
0,91\end{array}$ & & \multicolumn{2}{|c|}{$\begin{array}{l}\text { Number of obs }=7654 \\
F(12,7642)=16106,50 \\
\text { Prob }>F=0,0000 \\
\text { R-Squared }=0,9620 \\
\text { Adj R-Squared }=0,9619 \\
\text { Root } M S E=0,95553\end{array}$} \\
\hline LOGRDPC & Coef. & Std.Err. & $t$ & $P>|t|$ & \multicolumn{2}{|c|}{ [95\% conf. INTERVAL] } \\
\hline AGUA & 0,375 & 0,0346 & 10,84 & 0,000 & 0,307 & 0,443 \\
\hline ELETRICA & 1,424 & 0,0529 & 26,9 & 0,000 & 1,320 & 1,527 \\
\hline GEL & 0,394 & 0,0365 & 10,81 & 0,000 & 0,323 & 0,466 \\
\hline MAQLAV & 0,484 & 0,0293 & 16,5 & 0,000 & 0,426 & 0,541 \\
\hline RADIO & 0,660 & 0,0310 & 21,33 & 0,000 & 0,600 & 0,721 \\
\hline TVCORES & 0,245 & 0,0360 & 6,81 & 0,000 & 0,174 & 0,315 \\
\hline FREEZER & 0,242 & 0,0345 & 7 & 0,000 & 0,174 & 0,309 \\
\hline COMP & 0,429 & 0,0671 & 6,39 & 0,000 & 0,298 & 0,561 \\
\hline MCPINT & 0,376 & 0,0780 & 4,82 & 0,000 & 0,223 & 0,529 \\
\hline DENS & 0,200 & 0,0092 & 21,85 & 0,000 & 0,182 & 0,218 \\
\hline N_QUARTOS & 0,412 & 0,0119 & 34,7 & 0,000 & 0,389 & 0,435 \\
\hline N_BANHEIROS & 0,273 & 0,0202 & 13,5 & 0,000 & 0,233 & 0,313 \\
\hline
\end{tabular}

Coeficientes estimados para a $8^{\text {a }}$ série

\begin{tabular}{|c|c|c|c|c|c|c|}
\hline Source & SS & df & MS & & \multirow{4}{*}{\multicolumn{2}{|c|}{$\begin{array}{l}\text { Number of obs }=6619 \\
F(12,6607)=20681,47 \\
\text { Prob }>F=0,0000 \\
\text { R-Squared }=0,9741 \\
\text { Adj R-Squared }=0,9740 \\
\text { Root } M S E=0,84248\end{array}$}} \\
\hline Model & 176150,45 & 12 & 14679,20 & & & \\
\hline Residual & 4689,49 & 6607 & 0,71 & & & \\
\hline Total & 180839,935 & 6619 & 27,32 & & & \\
\hline LOGRDPC & Coef. & Std.Err. & $t$ & $P>|t|$ & \multicolumn{2}{|c|}{ [95\% conf. INTERVAL] } \\
\hline AGUA & 0,398 & 0,040 & 9,98 & 0,000 & 0,320 & 0,477 \\
\hline ELETRICA & 2,567 & 0,067 & 38,35 & 0,000 & 2,435 & 2,698 \\
\hline GEL & 0,264 & 0,042 & 6,23 & 0,000 & 0,181 & 0,346 \\
\hline MAQLAV & 0,349 & 0,026 & 13,68 . & 0,000 & 0,299 & 0,399 \\
\hline RADIO & 0,687 & 0,034 & 20,01 & 0,000 & 0,620 & 0,755 \\
\hline TVCORES & 0,132 & 0,042 & 3,15 & 0,002 & 0,050 & 0,214 \\
\hline FREEZER & 0,173 & 0,029 & 6,02 & 0,000 & 0,116 & 0,229 \\
\hline COMP & 0,359 & 0,051 & 6,98 & 0,000 & 0,258 & 0,460 \\
\hline MCPINT & 0,384 & 0,058 & 6,59 & 0,000 & 0,270 & 0,498 \\
\hline DENS & 0,055 & 0,011 & 5,05 & 0,000 & 0,034 & 0,076 \\
\hline N_QUARTOS & 0,209 & 0,013 & 15,8 & 0,000 & 0,183 & 0,235 \\
\hline N_BANHEIROS & 0,282 & 0,017 & 16,21 & 0,000 & 0,248 & 0,316 \\
\hline
\end{tabular}




\section{Anexo B - Especificação do modelo}

\section{Modelo com Efeito de Interação Cor/raça e Capitais}

$y_{i j}=\alpha_{0 j}+\alpha_{0 p p}^{*} I(i$ é Pardo $)+\alpha_{0 p}^{*} I(i$ é Preto $)+\beta_{1 j} n s e_{i j}+\beta_{2}$ Defas $_{i j}+\beta_{3}$ Defas $_{i j}{ }_{i j}+\beta_{4}$ Adian $_{i j}$ $\beta_{5} \operatorname{Re~pet~}_{i j}+\beta_{6}$ Masc $_{i j}+\alpha_{1 p p}^{*} I(i$ é Pardo $) * n^{*} e_{i j}+\alpha_{1 p}^{*} I(i$ é Preto $) * n s e_{i j}+e_{i j}$

$\alpha_{0 j}=\alpha_{0}+\alpha_{01} n s e_{j}+\alpha_{02}$ Par $_{j}+u_{0 j}$

$\beta_{1 j}=\alpha_{10}+u_{1 j}$

$e_{i j} \sim N\left(0, \sigma_{e}^{2}\right)$

$u_{0 j} \sim N\left(0, \sigma_{u 0}^{2}\right)$

$u_{1 j} \sim N\left(0, \sigma_{u 1}^{2}\right)$

$\operatorname{cov}\left(e_{i j}, u_{0 j}\right)=\operatorname{cov}\left(e_{i j}, u_{1 j}\right)=0$

Onde:

$y_{i j}=$ desempenho do aluno $i$ na escola $j$;

$\alpha_{0_{j}}=$ desempenho médio da escola j;

$\beta_{l j}=$ efeito da variável de nível socioeconômico dos alunos relativo à escola $j$;

$\alpha_{0}=$ desempenho médio geral;

$\alpha^{*}{ }_{0 p p}=$ desempenho médio geral dos alunos pardos;

$\alpha{ }_{0 p p}=$ desempenho médio geral dos alunos pretos;

$\alpha_{01}=$ efeito da variável de nível socioeconômico médio dos alunos das escolas;

$\alpha_{I 0}=$ efeito da variável de nível socioeconômico médio dos alunos nas escolas.

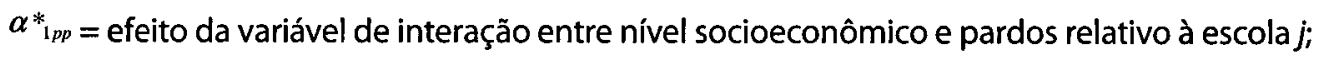

$\alpha_{1 p}^{*}=$ efeito da variável de interação entre nível socioeconômico e pretos relativo à escola $j ;$

$n s e_{j}=$ nível socioeconômico médio da escola $j ;$

$n s e_{i j}=$ nível socioeconômico do aluno $i$ relativo ao nível socioeconômico médio da escola j;

$I_{\mathrm{i}}=$ função indicadora de cor/raça. 


\section{Anexo C - Resultados dos modelos estimados}

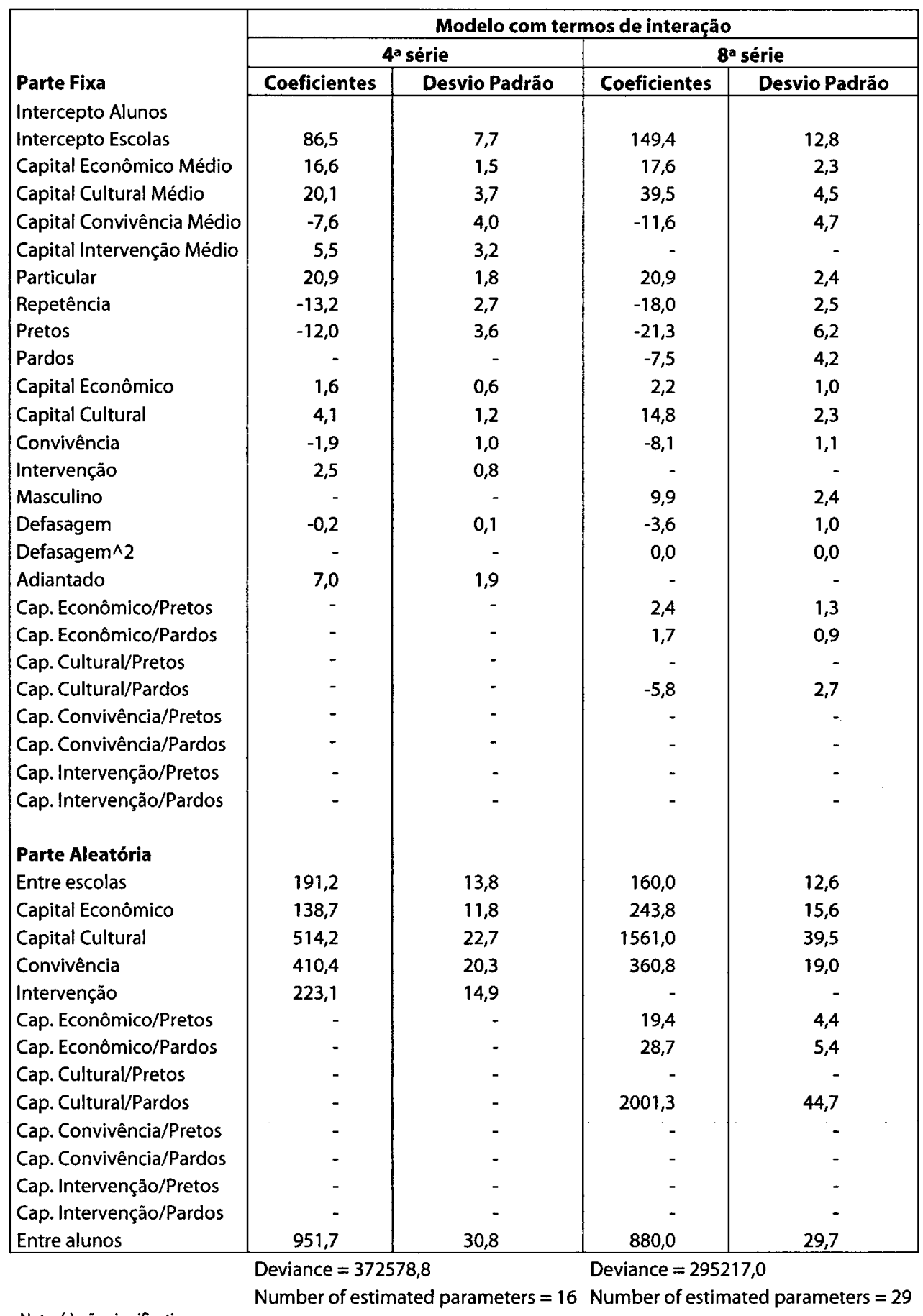

